\title{
Assessing the links between organisational cultures and unlearning capability: evidence from the Spanish automotive components industry
}

\author{
Antonio Luis Leal-Rodríguez* \\ Universidad Loyola Andalucía, \\ C/ Energía Solar, 1, \\ 41014 Sevilla, Spain \\ Email: alleal@uloyola.es

\section{José Antonio Ariza-Montes and Emilio J. Morales-Fernández} \\ Universidad Loyola Andalucía, \\ C/ Escritor Castilla Aguayo, 4, \\ 14004 Córdoba, Spain \\ Email: ariza@uloyola.es \\ Email: emorales@uloyola.es

\section{Stephen Eldridge} \\ Lancaster University, \\ Bailrigg, Lancaster, LA1 4YW, UK \\ Email: s.eldridge@lancaster.ac.uk
}

\begin{abstract}
Within the current business environment, knowledge management, organisational learning and unlearning mechanisms are becoming critical factors in the process of reaching lasting competitive advantages. Our research model employs the competing values framework (Cameron and Quinn, 1999) to empirically assess the influence of the firm's own cultural typology on organisational unlearning. Our hypotheses are tested using a sample of 145 firms drawn from the Spanish automotive components manufacturing sector. The relationships between the constructs are assessed through the use of partial least squares (PLS) path-modelling, a variance-based structural equation modelling technique. The outcomes reveal that certain types of culture exert a higher influence on unlearning than others. This suggests in turn that some cultural typologies are better positioned to face the current turbulent situation than others.
\end{abstract}

Keywords: organisational unlearning; organisational culture; automotive components industry; cultural typologies; partial least squares; PLS.

Reference to this paper should be made as follows: Leal-Rodríguez, A.L., Ariza-Montes, J.A., Morales-Fernández, E.J. and Eldridge, S. (xxxx) 'Assessing the links between organisational cultures and unlearning capability: evidence from the Spanish automotive components industry', Int. J. Innovation and Learning, Vol. X, No. Y, pp.000-000. 
Biographical notes: Antonio Luis Leal-Rodríguez holds a $\mathrm{PhD}$ with international mention in Economic Sciences and Management from Universidad de Sevilla. His research lines involve the assessment of organisational knowledge absorptive capacity and its impact on the innovation outcomes, as well as the analysis of organisational learning and unlearning mechanisms. He has developed a six months research visit to Lancaster University Management School. Currently, he is Lecturer and researcher at Universidad Loyola Andalucía.

José Antonio Ariza-Montes holds a $\mathrm{PhD}$ in Economic Sciences and Management from Universidad de Córdoba. His research interests deal with organisational theory, human resource management (HRM) and strategic business management. He holds a broad experience of advisory and strategic consulting for several institutions both public and private. Currently, he is Lecturer and researcher at Universidad Loyola Andalucía.

Emilio J. Morales-Fernández holds a $\mathrm{PhD}$ in Economic Sciences and Management from Universidad de Córdoba. His research interests include organisational theory, human resource management (HRM) and strategic business management. He holds a broad experience of advisory and strategic consulting for several institutions both public and private. Currently, he is Lecturer and researcher at Universidad Loyola Andalucía.

Stephen Eldridge is Senior Teaching Fellow at Lancaster University (UK). His research interests lie in the deployment of process improvement techniques and knowledge management in organisations, particularly those in the manufacturing and logistics sectors. He has long standing collaborations with colleagues in Spanish and Dutch institutions.

This paper is a revised and expanded version of a paper entitled 'Linking organizational culture typologies with unlearning capability: the case of Spanish automotive components manufacturers' presented at XXV Jornadas Hispanolusas de Gestión Científica, Ourense, Spain, 5-6 February 2015.

\section{Introduction}

Nowadays, firms ought to be ready to adapt to the continuously changing economic environment. In such a dynamic scenario, knowledge easily becomes obsolete. Therefore, organisations need to face this complexity by regularly renewing their knowledge bases. According to Sanz-Valle et al. (2011), organisational learning (OL) plays a critical role in this renewal. Thus, being innovative and fostering OL processes and routines can lead organisations to reach lasting competitive advantages and hence, obtaining better performance than its competitors.

According to Senge (1990), fostering organisational learning mechanisms - the capacity to learn faster than competitors - is perhaps the only way of developing innovative products, services and processes within firms, and hence, reaching lasting competitive advantages. However, Akgün et al. (2007), point out that OL by itself is not sufficient for the development and fostering of organisational knowledge and insight. These authors posit that in order to being able to renew their knowledge repositories, organisations should also rely on organisational unlearning (OU) mechanisms. 
Prior studies attempted to identify the major drivers of learning and innovation processes at the organisational level. Organisational culture (OC) is among these critical drivers and several studies have addressed the links between OC and OL within firms (De Long and Fahey, 2000; Sanz-Valle et al., 2011). Nevertheless, this research needs to be supplemented with evidence of the relationship between $\mathrm{OC}$ and organisational unlearning $(\mathrm{OU})$ in order to enable a more complete understanding of this phenomenon. Consequently, we aim to assess the links among the different OC typologies with OU processes, relying on the competing values framework (CVF) proposed by Cameron and Quinn (1999).

The paper is structured as follows. Section 2 presents the theoretical background, involving the research model and hypotheses arising from the literature review. Section 3 describes the research methodology followed in order to test the hypotheses. Section 4 describes the results derived from the data analysis. Finally, Section 5 brings up the discussion and conclusions of this study.

\section{Research model and hypotheses}

\subsection{Linking organisational culture typologies with unlearning}

Organisational culture can be defined as a joint set of beliefs, assumptions, prospects and essential principles shared by the members of an organisation. Such set of beliefs and expectations produce rules that powerfully shape the behaviour of individuals and groups within the firm, and hence, contribute to differentiate it from other organisations (Leal, 1991). This study approaches OC from the CVF proposed by Cameron and Quinn (1999).

This model involves two dimensions: the first dimension relates to formal and informal processes and the second entails the strategic focus. Formal processes are characterised by high doses of control, order and stability, whereas informal processes involve a greater degree of laxity and flexibility. The strategic focus dimension contrasts internal integration with external adaptation and differentiation. From this point of view, Desphande et al. (1993) argue that internally oriented cultures may provoke a lack of attention to the market changes which constitute an essential issue in KM and innovation processes. Firms with an externally oriented culture will find it easier to obtain key external information that may enable these capabilities. These two dimensions mapped together against each other in the CVF, shape four different cultural typologies: clan culture, adhocracy culture, hierarchy culture and market culture (Figure 1). Each of these cultures comprises distinctive particularities that conduct them to enabling or hindering OU mechanisms within firms.

Clan culture is usually linked to the following labels: familiarity, reliability, loyalty, empowerment and collegiality (Cameron and Quinn, 1999). Other crucial foundations are decentralisation and flexibility, which imply both greater participation and self-control. This OC principally focuses on human resources and morale to the extent that its key values are rooted on the firm's concern for its employees and guaranteeing positive working relationships. According to Keskin (2005), within these firms, organisational cohesiveness and personal satisfaction are more important than financial and market objectives. The firm's commitment to humane treatment and development fits well with the learning-oriented and knowledge-sharing philosophies. However, the strong emphasis on people issues might be a handicap for the implementation OU mechanisms. 
Figure 1 The CVF

Flexibility and discretion

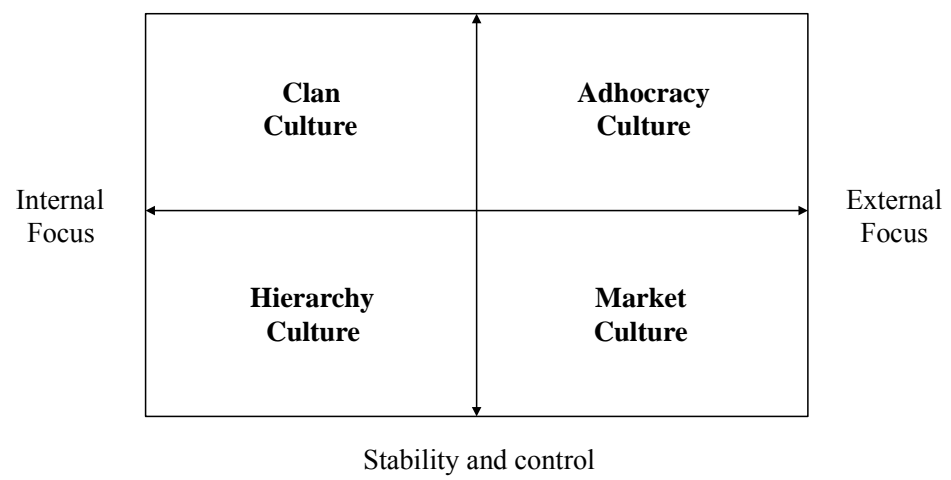

Adhocracy culture is usually linked to the following tags: creativity, dynamism, entrepreneurship, innovation, aggressiveness, adaptability and readiness for change. Firms that possess this type of OC seek efficiency while focusing on innovation, growth and new resources (Desphande et al., 1993). Prior studies point out that this culture is based on values such as risk tolerance (Tellis et al., 2009; Cooper et al., 2004) and commitment to learning (McLaughlin, 2002). Thus, firms with an adhocratic culture are able to respond quicker to changes in their environment and are ready to assume higher risks.

As for the case of clan culture, market culture also presents a hybrid situation. While a dimension drives OU (commitment to the market needs and changes, for example through the orientation towards competitiveness and differentiation), the other hinders it (the desire for control). This $\mathrm{OC}$ is characterised for having goal-orientation, results-orientation, productivity, efficiency and competitiveness as its predominant values. Market culture emphasises gaining reputation and success and the strong competitiveness that characterises it could lead to the development of OU, as striving for efficiency requires continuous improvement. However, the second dimension of a market culture is oriented towards control rather than flexibility, which in turn imply formal control mechanisms involving compliance with certain rules and standards. This may limit and inhibit creativity, which is in turn, one of the requirements that enable unlearning.

Finally, hierarchy culture is often labelled as bureaucratic, rule-based, by-the-book, and top-down (Zammuto et al., 2000). This cultural typology is sustained by marginal ambiguity levels and by an excessive sense of stability, uniformity, safety, efficiency and predictability. This culture maintains a permanent concern for order and control by means of strict rules, procedures or instructions. Furthermore, this cultural typology internally focused, and hence, makes firms more oriented to prioritise and devote to the rigid hierarchical structure rather than seeking new knowledge and innovative opportunities in the market.

Cegarra-Navarro et al. (2012) broadly conceptualise unlearning as the process by which firms remove old logics and behaviours and make room for new ones. Prior related works define this concept as "the process of reducing or eliminating pre-existing knowledge or habits" [Akgün et al., (2002), p.60], or "the process by which individuals 
and organizations acknowledge and release prior learning in order to accommodate new information and behaviors" [Becker, (2005), p.661]. This study approaches unlearning from the angle proposed by Cegarra and Sánchez (2008), that considers OU as a second order construct shaped by three dimensions:

1 the examination of lens fitting

2 the framework for changing individual habits

3 the framework for consolidating emergent understandings.

Several studies have addressed the links between organisational culture and organisational learning. Nevertheless, the literature linking cultural typologies and organisational unlearning still remain scarce. Büschgens et al. (2013) suggest that OC is a key to innovation success. There is strong evidence related to the positive relationship between OC and firm innovativeness (Desphande et al., 1993; Hernández-Mogollon et al., 2010). As well as organisations that really intend to be innovative ought to have an OC that strongly supports innovation; OU should also be enabled through the firm's cultural typology (Santos-Vijande and Álvarez-González, 2007). In this sense, different styles of OC will directly influence OL and organisational innovation (Liao et al., 2012) but further research is needed concerning the link between OC and OU.

$\mathrm{OL}$ is a dynamic cycle that comprises a succession of knowledge absorption and knowledge forgetting processes. In this vein, once acknowledged that OU constitutes a stage of the OL process, it leads us to assess the impact of OC on OU. In this line, De Long and Fahey (2000) recognise four ways in which OC exerts an impact on OL. The first way assumes that OC shapes employees' assumptions about whether knowledge remains significant and what knowledge turns out to be useless and should be put aside. A second way sustains that $\mathrm{OC}$ enables incorporating individual knowledge into the firm's knowledge base. Another way posits that new knowledge is created, legitimated and disseminated on the basis of the firm's OC. Finally, OC enables a context for social interaction that ultimately defines the firms' efficiency while creating, sharing and applying knowledge. Accordingly, different organisational cultures may exert different influences on OL and OU.

With regard to the above exposed, it can be argued that OC that promote creativity, dynamism, competitiveness, and differentiation and that are strategically oriented to predict and satisfy market fluctuations will enable OU. Instead, OC that emphasise formal processes and are based upon stability, control, order and bureaucracy may hinder OU. In this vein, adhocracy and market cultures are expected to have a positive impact on OU. Furthermore, the combination of the internal focus with a greater emphasis on formal and regulated processes causes the inability of firms with a hierarchical culture to unlearn. Finally, despite clan culture comprises a high level of flexibility, which could enable unlearning, its little degree of external orientation makes it unlikely to foster OU. Therefore, our study proposes the following hypotheses that are illustrated in Figure 2:

H1 Organisational culture will affect organisational unlearning. In particular:

H1a Clan culture is negatively linked to organisational unlearning.

H1b Adhocracy culture is positively linked to organisational unlearning.

H1c Market culture is positively linked to organisational unlearning.

H1d Hierarchy culture is negatively linked to organisational unlearning. 
Figure 2 Research model and hypotheses

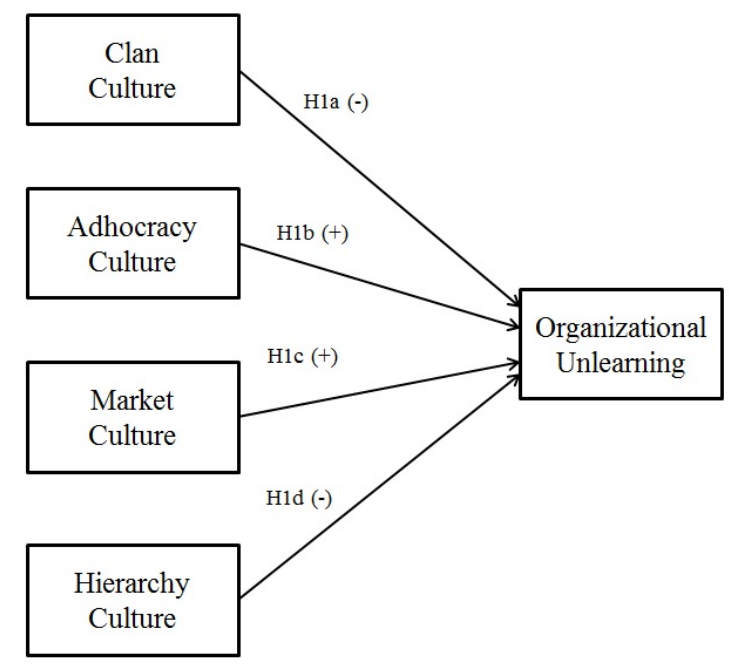

\section{Method}

\subsection{Data collection and sample}

Data for this research comes from a survey conducted in 2013. The population includes companies belonging to the automotive components manufacturing sector in Spain. We drew the sample from a list obtained from the Spanish Association of Manufacturers of Equipment and Components for the Automotive Industry (SERNAUTO). This sector comprises a total of 906 companies, from which we identified 418 that fulfilled our selection criteria (i.e., being knowledge-intensive firms that pursue learning and innovation). After two mailing efforts, we obtained 145 usable surveys (i.e., a 34.7\% response rate). The respondents were CEOs or senior executives of the sample firms.

\subsection{Measures}

The survey design adapted previously used and validated scales where the items and responses appear on a seven-point Likert scale, ranging from 1 (completely disagree) to 7 (completely agree). OC is measured on the basis of the organisational culture assessment instrument (OCAI) developed by Cameron and Quinn (1999). This scale uses six key dimensions of four items each (i.e., a total of 24 items). OU is measured as an aggregate multidimensional (second order) construct, we used a scale that uses 18 items (five items to measure the examination of lens fitting, six items to measure the consolidation of emergent understanding, and seven items to measure the framework for changing individual habits) proposed by Cegarra and Sánchez (2008). The scales are fully provided in the Appendix. 
Assessing the links between organisational cultures and unlearning capability 7

\subsection{Data analysis}

To test the research model and hypotheses, we rely on the use of partial least squares (PLS) path-modelling, a variance-based structural equation modelling (SEM) method. PLS is an appropriate method for this study due to the subsequent reasons (Roldán and Sánchez-Franco, 2012):

1 the sample size $(\mathrm{n}=145)$ is small

2 the study is oriented to predicting the dependent variables.

We used the SmartPLS software (Ringle et al., 2005) in order to assess both the measurement and the structural models.

\section{Results}

The assessment and interpretation of PLS models involve two stages:

1 evaluating the reliability and validity of the measurement model

2 assessing the significance of the relationships posited on the structural model.

\subsection{Measurement model}

Evaluating reflective measurement models comprises the assessment of the model's reliability and validity. Results show that the measurement model meets all common requirements. Firstly, reflective individual items are reliable, as all standardised loadings surpass the critical level of 0.707 (Table 1). In consequence, the individual items reliability is adequate (Carmines and Zeller, 1979). Secondly, all reflective constructs achieve construct reliability, since their composite reliabilities $(\rho c)$ are greater than 0.7 (Nunnally and Bernstein, 1994) (Table 1). Additionally, these latent variables achieve convergent validity because their average variance extracted (AVE) surpasses the 0.5 level (Fornell and Larcker, 1981) (Table 1). Finally, all variables meet the requirements of discriminant validity, which is observed through the comparison of the square root of AVE versus the corresponding latent variable correlations (Table 2). For satisfactory discriminant validity, the diagonal elements should be significantly greater than the off-diagonal elements in the corresponding rows and columns (Roldán and Sánchez-Franco, 2012).

The assessment of formative measurement models at the indicator level comprises the test for potential multicollinearity between items, as well as the assessment of weights (Henseler et al., 2009). We used the IBM-SPSS software to perform collinearity tests. The maximum variance inflation factor (VIF) values for the manifest variables (dimensions) that shape OU are 4.841, 2.327, and 4.829, respectively (Table 3), well within the acceptable threshold of 5 (Hair et al., 2011). Additionally, weights provide information about the extent to which each formative dimension contributes to the $\mathrm{OU}$ construct. Hence, weights actually yield a ranking of these dimensions according to their contribution (Henseler et al., 2009). Table 3 reveals that the examination of lens fitting (0.404) and the consolidation of emergent understandings (0.396) represent the most significant dimensions in the composition OU. 
Table 1 Reflective measurement model

\begin{tabular}{|c|c|c|c|}
\hline Construct/indicator & Loading & $\begin{array}{c}\text { Composite reliability } \\
(C R)\end{array}$ & $\begin{array}{l}\text { Average variance } \\
\text { extracted (AVE) }\end{array}$ \\
\hline Adhocracy culture & & 0.9554 & 0.7814 \\
\hline $\mathrm{ac} 1$ & 0.8883 & & \\
\hline ac2 & 0.8691 & & \\
\hline ac3 & 0.9142 & & \\
\hline ac4 & 0.9204 & & \\
\hline ac5 & 0.8694 & & \\
\hline ac6 & 0.8398 & & \\
\hline Clan culture & & 0.8774 & 0.5508 \\
\hline $\mathrm{cc} 1$ & 0.8417 & & \\
\hline $\operatorname{cc} 2$ & 0.7819 & & \\
\hline $\operatorname{cc} 3$ & 0.4662 & & \\
\hline $\operatorname{cc} 4$ & 0.7951 & & \\
\hline $\operatorname{cc} 5$ & 0.7394 & & \\
\hline $\operatorname{cc} 6$ & 0.7674 & & \\
\hline Market culture & & 0.9613 & 0.8058 \\
\hline $\mathrm{mc} 1$ & 0.9026 & & \\
\hline $\mathrm{mc} 2$ & 0.9263 & & \\
\hline $\mathrm{mc} 3$ & 0.8983 & & \\
\hline $\mathrm{mc} 4$ & 0.8313 & & \\
\hline $\operatorname{mc} 5$ & 0.8943 & & \\
\hline mc6 & 0.9296 & & \\
\hline Hierarchy culture & & 0.9258 & 0.6762 \\
\hline hc1 & 0.8398 & & \\
\hline hc2 & 0.7548 & & \\
\hline hc3 & 0.8897 & & \\
\hline he4 & 0.8021 & & \\
\hline hc5 & 0.8895 & & \\
\hline hc6 & 0.7458 & & \\
\hline
\end{tabular}

Note: $\mathrm{p}<0.001$ (based on $\mathrm{t}(4999)$, two-tailed test).

Table 2 Discriminant validity

\begin{tabular}{lccccc}
\hline & $A C$ & $C C$ & $H C$ & $M C$ & $O U$ \\
\hline AC & 0.8840 & 0 & 0 & 0 & 0 \\
CC & -0.2981 & 0.7422 & 0 & 0 & 0 \\
HC & -0.4029 & 0.689 & 0.8223 & 0 & 0 \\
MC & -0.5751 & 0.2414 & 0.2384 & 0.8977 & 0 \\
OU & -0.3636 & -0.0815 & 0.0275 & 0.7393 & N.A. \\
\hline
\end{tabular}

Note: N.A.: not applicable 
Assessing the links between organisational cultures and unlearning capability 9

Table 3 Formative measurement model

\begin{tabular}{|c|c|c|c|c|c|}
\hline Construct/dimension/indicator & $V I F$ & Weight & Loading & $\begin{array}{c}\text { Composite } \\
\text { reliability } \\
(C R)\end{array}$ & $\begin{array}{c}\text { Average } \\
\text { variance } \\
\text { extracted (AVE) }\end{array}$ \\
\hline Organisational unlearning & & & & N.A. & N.A. \\
\hline Examination of lens fitting & 4.841 & 0.404 & & 0.959 & 0.824 \\
\hline oula & & & 0.909 & & \\
\hline oulb & & & 0.909 & & \\
\hline oulc & & & 0.900 & & \\
\hline ould & & & 0.881 & & \\
\hline oule & & & 0.939 & & \\
\hline $\begin{array}{l}\text { Consolidation of emergent } \\
\text { understandings }\end{array}$ & 2.327 & 0.396 & & 0.923 & 0.666 \\
\hline ou $2 \mathrm{a}$ & & & 0.821 & & \\
\hline ou $2 b$ & & & 0.826 & & \\
\hline ou $2 \mathrm{c}$ & & & 0.776 & & \\
\hline ou $2 d$ & & & 0.846 & & \\
\hline ou $2 \mathrm{e}$ & & & 0.766 & & \\
\hline ou $2 \mathrm{f}$ & & & 0.857 & & \\
\hline $\begin{array}{l}\text { Framework for changing } \\
\text { the individual habits }\end{array}$ & 4.829 & 0.353 & & 0.973 & 0.839 \\
\hline ou3a & & & 0.937 & & \\
\hline ou3b & & & 0.921 & & \\
\hline ou3c & & & 0.908 & & \\
\hline ou3d & & & 0.904 & & \\
\hline ou3e & & & 0.913 & & \\
\hline ou3f & & & 0.910 & & \\
\hline ou3g & & & 0.917 & & \\
\hline
\end{tabular}

Notes: N.A.: not applicable. $\mathrm{p}<0.001$ (based on $\mathrm{t}(4999)$, two-tailed test).

\subsection{Structural model}

Table 4 shows the explained variance (R2) in the endogenous variables and the path coefficients for the model under study. Bootstrapping (5000 samples) provides t-values that allow the evaluation of the statistical significance of the relationships in the research model (Roldán and Sánchez-Franco, 2012).

Results for the structural model, as revealed by Table 4, provide evidence to support the following hypotheses: H1a and H1c. However, hypotheses H1b and H1d are not supported. 
Table 4 Structural model results

\begin{tabular}{lcccc}
\hline \multirow{2}{*}{ Relationship } & Path coefficient & \multicolumn{2}{c}{ Percentile bootstrap 95\% CI } & \multirow{2}{*}{ Support } \\
\cline { 3 - 4 } & & Lower & Upper & \\
\hline $\mathrm{R}^{2} \mathrm{OU}=0.617$ & & & \\
$\mathrm{R}^{2} \mathrm{IO}=0.761$ & & & \\
$\mathrm{H} 1 \mathrm{a}:$ Clan $\rightarrow$ OU & $-0.324^{* *}(2.876)$ & -0.516 & -0.070 & Yes \\
H1b: Adhoc $\rightarrow$ OU & $0.042 \mathrm{~ns}(0.391)$ & -0.216 & 0.208 & No \\
H1c: Market $\rightarrow$ OU & $0.819^{* * *}(13.467)$ & 0.671 & 0.913 & Yes \\
H1d: Hier $\rightarrow$ OU & $0.062 \mathrm{~ns}(0.674)$ & -0.147 & 0.213 & No \\
\hline
\end{tabular}

Notes: $\mathrm{t}$ values in parentheses; ${ }^{* * *} \mathrm{p}<0.001 ;{ }^{*} \mathrm{p}<0.01 ;{ }^{*} \mathrm{p}<0.05$; ns: not significant; based on $\mathrm{t}(4999)$, one-tailed test. $\mathrm{t}(0.05,4999)=1.645 ; \mathrm{t}(0.01,4999)=2.327$; $\mathrm{t}(0.001,4999)=3.092$.

\section{Discussion and conclusions}

The purpose of this paper was to shed light upon the existing relationships among the distinct cultural typologies and organisational unlearning. This study was carried out on the basis of a sample drawn in the ACMS sector. Results obtained by applying PLS-SEM, a SEM technique, reveal that, as expected, different OC exert diverse impacts on OU. In this vein, we offer evidence that supports the negative relationship between clan culture and OU. Although this cultural typology emphasises familiarity, paternalism and trust among the company members, which may encourage information and knowledge sharing, its excessive internal focus may suppose an alienating vision of reality, as it does not contemplates the changes in consumers' needs and behaviours. Therefore, these firms are not prepared to unlearn, as unlearning often requires challenging the routines, processes and thought patterns that worked well in the past. On the other hand, accordingly with the results derived from our study, it is supported that market culture is positively linked to OU. This is due to the clear external orientation that this culture holds. Being in narrow contact with market changes and tendencies enables firms to anticipate what customers demand. Thus, these firms are used to constantly evolve with the market. Being able to recognise which knowledge remains useful and what knowledge should be discarded is among the essentials of unlearning.

We also hypothesised the existence of a positive link between adhocracy culture and unlearning (H1b) and the existence of a negative link between hierarchy culture and OU (H1d). Despite there is some evidence in the literature that supports the links among these cultural typologies and firm innovativeness (Sanz-Valle et al., 2011), our results does not provide evidence for these hypotheses.

In conclusion, firms that foster competitiveness and that maintain themselves in constant alert to the market challenges are more likely to identify and attract interesting opportunities that might lead to beneficial outcomes. Unlearning might be the first step in order to being able to learn. A continuous and dynamic learning and unlearning approach lead firms to deal better with the turbulence and volatility that characterises their current business environment, and therefore enables them to achieve and sustain long-term competitive advantages. 
The managerial and practical implications are clear. In this vein, we aim to highlight the importance of embracing $\mathrm{OU}$ as a proactive strategy, enabling firms to anticipate and effectively react to changes within the sector, technological advancements, or the anticipation of customers' new needs and demands, with the end purpose of differentiating the firm from its competitors, and hence, improving its business performance. Therefore, the adoption of an OC that stresses and facilitates unlearning should be widely promoted among these firms.

Certainly, the analysis presents some limitations. For instance, it only considers companies belonging to a particular sector (i.e. the ACMS) and within a particular geographical context (Spain). Therefore, researchers must be cautious while generalising these results. Secondly, although we provide evidence of causality, causality itself has not been proven. Accordingly to Fornell (1982), causal relationship between variables cannot be proven, as they are always assumed by the researcher. Thirdly, this research relies on individual (the surveyed) perceptions and we only used a single method to elicit these perceptions. On the other hand, concerning some further research areas to develop, it might be interesting to investigate in depth what are the main drivers and enablers of an unlearning-oriented organisational culture. To this aim, perhaps a case study might be useful, as it may provide us insights and qualitative data helpful to sustain and validate our research.

\section{Acknowledgements}

This paper was awarded the best work of the Conference on the Innovation and Knowledge Management Track.

\section{References}

Akgün, A., Byrne, J., Lynn, G. and Keskin, H. (2007) 'New product development in turbulent environments: impact of improvisation and unlearning on new product performance', Journal of Engineering and Technology Management, Vol. 24, No. 3, pp.203-230.

Akgün, A.E., Lynn, G.S. and Reilly, R. (2002) 'Multi-dimensionality of learning in new product development teams', European Journal of Innovation Management, Vol. 5, No. 2, pp.57-72.

Becker, K. (2005) 'Individual organizational unlearning: directions and future research', International Journal of Organisation Behaviour, Vol. 9, No. 7, pp.659-670.

Büschgens, T., Bausch, A. and Balkin, D.B. (2013) 'Organizational culture and innovation: a meta-analytic review', Journal of Product Innovation Management, Vol. 30, No. 4, pp.763-781.

Cameron, K. and Quinn, R. (1999) Diagnosing and Changing Organizational Culture. Based on the Competing Values Framework, Addison-Wesley, Boston, MA.

Carmines, E.G. and Zeller, R.A. (1979) 'Reliability and validity assessment. Sage university paper series on quantitative applications in the social sciences', Vol. 7, No. 17, Sage, Beverly Hills, CA.

Cegarra, J.G. and Sanchez, M. (2008) 'Linking the individual forgetting context with customer capital from a seller's perspective', Journal of the Operational Research Society, Vol. 59, No. 12, pp.1614-1623.

Cegarra-Navarro, J.G., Eldridge, S. and Gamo Sánchez, A.L. (2012) 'How an unlearning context can help managers overcome the negative effects of counter-knowledge', Journal of Management \& Organization, Vol. 18, No. 2, pp.231-246. 
Cooper, R.G., Edgett, S.J. and Kleinschmidt, E.J. (2004) 'Benchmarking best NPD practices-1', Research-Technology Management, Vol. 47, No. 1, pp.31-43.

De Long, D. and Fahey, L. (2000) 'Diagnosing cultural barriers to knowledge management', Academy of Management Executive, Vol. 14, No. 4, pp.113-127.

Desphande, R., Farley, J.U. and Webster Jr., F.E. (1993) 'Corporate culture, customer orientation and innovativeness in Japanese firms: a quadrad analysi', Journal of Marketing, Vol. 57, No. 1, pp.23-57.

Fornell, C. (1982) 'A second generation of multivariate analysis: an overview', in Fornell, C. (Ed.): A Second Generation of Multivariate Analysis, Vol. 1, pp.1-21, Praeger, New York, NY.

Fornell, C. and Larcker, D.F. (1981) 'Evaluating structural equation models with unobservable variables and measurement error', Journal of Marketing Research, Vol. 18, No. 1, pp.39-50.

Hair, J.F., Ringle, C.M. and Sarstedt, M. (2011) 'PLS-SEM: indeed a silver bullet', Journal of Marketing Theory and Practice, Vol. 19, No. 2, pp.137-149.

Henseler, J., Ringle, C.M. and Sinkovics, R.R. (2009) 'The use of partial least squares path modeling in international marketing', Advances in International Marketing, Vol. 20, pp.277-320.

Hernández-Mogollon, R., Cepeda-Carrión, G., Cegarra-Navarro, J.G. and Leal-Millán, A. (2010) 'The role of cultural barriers in the relationship between open-mindedness and organizational innovation', Journal of Organizational Change Management, Vol. 23, No. 4, pp.360-376.

Keskin, H., Akgün, A.E., Günsel, A. and İmamoğlu, S.Z. (2005) 'The relationships between adhocracy and clan cultures and tacit oriented KM strategy', Journal of Transnational Management, Vol. 10, No. 3, pp.39-53.

Leal, A. (1991) Conocer la cultura de las organizaciones: una base para la estrategia y el cambio, Actualidad Editorial, Madrid.

Liao, S.H., Chang, W.J., Hu, D.C. and Yueh, Y.L. (2012) 'Relationships among organizational culture, knowledge acquisition, organizational learning, and organizational innovation in Taiwan's banking and insurance industries', The International Journal of Human Resource Management, Vol. 23, No. 1, pp.52-70.

McLaughlin, H.M. (2002) The Relationship Between Learning Orientation, Market Orientation and Innovation and Their Effect on Organizational Performance, ProQuest Information and Learning, Ann Arbor, MI.

Nunnally, J.C. and Bernstein, I.H. (1994) Psychometric Theory, 3rd ed., McGraw-Hill, New York.

Ringle, C.M., Wende, S. and Will, A. (2005) SmartPLS 2.0 (M3) Beta, Hamburg.

Roldán, J.L. and Sánchez-Franco, M.J. (2012) 'Variance-based structural equation modelling: guidelines for using partial least squares in information systems research', in Mora, M. et al. (Eds.): Research Methodologies, Innovations and Philosophies in Software Systems Engineering and Information Systems, pp.193-221, IGI Global, Hershey, PA.

Santos-Vijande, L. and Álvarez-González, L.I. (2007) 'TQM and firms performance: an EFQM excellence model research based survey', International Journal of Business Science and Applied Management, Vol. 2, No. 2, pp.21-41.

Sanz-Valle, R., Naranjo-Valencia, J.C., Jiménez-Jiménez, D. and Perez-Caballero, L. (2011) 'Linking organizational learning with technical innovation and organizational culture', Journal of Knowledge Management, Vol. 15, No. 6, pp.997-1015.

Senge, P.M. (1990) The Fifth Discipline: The Art and Practice of the Learning Organization, Random House, London.

Tellis, G.J., Prabhu, J.C. and Chandy, R.K. (2009) 'Radical innovation across nations: the preeminence of corporate culture', Journal of Marketing, January, Vol. 73, pp.3-23.

Zammuto, R.F., Gifford, B. and Goodman, E.A. (2000) 'Managerial ideologies, organization culture and the outcomes of innovation: a competing values perspective', in Askhanasy, N.H., Wilderom, C.P.M. and Peterson, M.F. (Eds.): Handbook of Organizational Culture and Climate, Sage Publications, Thousand Oaks, CA. 
Assessing the links between organisational cultures and unlearning capability 13

\section{Appendix}

\section{Scales}

\section{A Organisational culture (OCAI) (Cameron and Quinn, 1999)}

1 My organisation is characterised for being...

- A very personal place, almost an extension of family.

- A very dynamic and entrepreneurial entity. People are willing to bet on their ideas and take risks.

- A very results-oriented entity. People are very competitive and achievement-oriented.

- A very hierarchical formalised and structured entity. Any activity is provided with previously established standards and procedures.

2 Leadership in my organisation...

- Is generally identified with orientation (mentoring), facilitation and support (nurturing).

- Is characterised by fostering entrepreneurship, innovation and risks assumption.

- Is characterised by having a practical, aggressive and results-oriented focus.

- Is characterised for promoting coordination, organisation, the good functioning (operation) and efficiency.

3 The management of the employees in my organisation...

- Is characterised by a management style based in teamwork, consensus and participation.

- Is characterised by promoting individual initiative, risk-taking, innovation, and uniqueness.

- Is characterised by promoting a competitive spirit, high demands and a clear orientation towards achievement.

- Is characterised by employment security, compliance, predictability and stability in relations.

4 The values shared by the staff in my organisation are...

- Mutual loyalty and trust. Great importance is given to the commitment to the organisation.

- The commitment to innovation, development and continuous change.

- The emphasis on achievement and the consecution of goals or objectives.

- Respect for and compliance with standards and formal policies to maintain the good functioning of the firm.

5 The strategic priorities in my organisation are...

- The development of the person, trust, honesty and participation.

- The acquisition of new resources and the creation of new challenges. Originality and the search for opportunities are appreciated. 
- The actions and competitive achievements. To gain market share is considered to be something predominant.

- Permanence, stability, efficiency, control, and the fluidity of the operations are important.

6 Success criteria in my organisation are based on...

- The development of the human resources, teamwork, the employee commitment and the concern for people.

- The development of unique and novelty products or services. We aspire to become leaders in production and innovation.

- Gaining market share and displacing the competitors. To become the market leader is the key.

- Efficiency. Reliable deliveries, refined programming and low cost represent fundamental aspects.

B Organisational unlearning (Cegarra and Sánchez, 2008)

1 In my company...

- Employees are able to easily identify problems (new ways of doing things).

- Employees are able to identify mistakes from their colleagues.

- Employees are able to listen to the customer (e.g.: complaints, suggestions...).

- Employees are able to easily share information with the managers.

- Employees try to reflect and learn from their own mistakes.

2 In my company...

- Managers seem to be open to new ideas and ways of doing things.

- Managers have tried to start projects.

- Managers recognise the value of acquiring, assimilating and applying new information.

- Managers adopt the employees' suggestions in the form of new routines and processes.

- Managers are willing to work together with the employees of the company and resolve problems together.

- Managers are concerned about the fact that the way to respond to unforeseen circumstances will be known by all.

3 In my company...

- The existence of new situations have helped individuals to identify their own mistakes.

- The existence of new situations have helped individuals to undesirable attitudes.

- The existence of new situations have helped individuals to identify behaviours improper for the place.

- Individuals recognise the forms of reasoning or to arrive at solutions such as inadequate. 
Assessing the links between organisational cultures and unlearning capability 15

- The existence of new situations have helped individuals to change their behaviours.

- The existence of new situations have helped individuals to change their attitudes.

- The existence of new situations have helped individuals to change their thoughts. 